\title{
Slowdown of the thermohaline circulation causes enhanced maritime climate influence and snow cover over Europe
}

\author{
Daniela Jacob, Holger Goettel, Johann Jungclaus, Michael Muskulus, Ralf Podzun, \\ and Jochem Marotzke \\ Max Planck Institute for Meteorology, Hamburg, Germany
}

Received 20 April 2005; revised 22 August 2005; accepted 27 September 2005; published 8 November 2005.

[1] The ocean thermohaline circulation (THC) in the Atlantic is generally accepted to contribute to the comparatively mild climate of western and northern Europe. Global climate models (Manabe and Stouffer, 1995; Vellinga and Wood, 2002) and palaeo-observations (McManus et al., 2004) associate periods of weak or absent Atlantic THC with considerably lower temperatures in and around the northern North Atlantic. However, it is uncertain whether such change would spread longitudinally around the globe or would be limited to a narrow strip near the coast (Vellinga and Wood, 2002; Mikolajewicz et al., 1997). Moreover, the relatively low spatial resolution of global climate models has prohibited more detailed statements about possible or probable THC-induced climate change in Europe. Here, we first use a global climate model to perform a THC-slowdown sensitivity experiment, with a weakening of the MOC by about $50 \%$, and the associated control experiment. The two global simulations are then used to force a regional climate model for Europe; the regional control and sensitivity simulations are analyzed here. We find stronger maritime influence over Europe than in the case with no MOC weakening, which surprisingly results in cooling (because sea surface temperatures drop), contrary to today's conditions, where maritime influence leads to milder conditions in Europe. Lower temperatures cause reduced precipitation, increased snow cover and higher albedo leading to positive feedback. Citation: Jacob, D., H. Goettel, J. Jungclaus, M. Muskulus, R. Podzun, and J. Marotzke (2005), Slowdown of the thermohaline circulation causes enhanced maritime climate influence and snow cover over Europe, Geophys. Res. Lett., 32, L21711, doi:10.1029/2005GL023286.

\section{Introduction}

[2] The major obstacles to more reliable assessments of the risk for Europe of THC-induced climate change lie in the widely varying projections of future THC change [Cubasch et al., 2001] and the limited spatial detail provided by global climate models. The first uncertainty is sidestepped here by inducing a THC weakening through an externally imposed additional freshwater flux into the northern North Atlantic, without rigorously justifying this addition as arising from a self-consistent climate scenario. This sensitivity study is carried out under pre-industrial greenhouse gas conditions, and it is consistent with the protocol defined within the Coupled Modelling Intercomparison Project (CMIP, http://www-pcmdi.llnl.gov/projects/

Copyright 2005 by the American Geophysical Union. 0094-8276/05/2005GL023286\$05.00 cmip/index.php). The amount of freshwater added, 0.1 Sv $\left(1 \mathrm{~Sv} \equiv 10^{6} \mathrm{~m}^{3} \mathrm{~s}^{-1}\right)$, can be visualised by noting that it corresponds to $1 / 6$ of the Greenland ice sheet melting over 100 years. This flux is larger than projected melting rates of the Greenland ice sheet under different greenhouse warming scenarios [Huybrechts and de Wolde, 1999; Greve, 2000], which correspond to additional freshwater fluxes of $0.01-$ $0.08 \mathrm{~Sv}$, but does not require the extreme scenario of, for example, a glacial meltwater lake to discharge catastrophically [Manabe and Stouffer, 1995; Vellinga and Wood, 2002; Fairbanks, 1989; Teller and Leverington, 2004; Clarke et al., 2004]. Instead, the perturbation freshwater flux corresponds to roughly a doubling of the freshwater input into the Nordic Seas and the Arctic Ocean [Aagard and Carmack, 1989].

\section{Model and Methods}

[3] The high-resolution focus of this study has been enabled through the nesting of a regional model into a global simulation of THC slowdown and its respective control experiment, which is novel for such a sensitivity experiment. The climate model system consists of the global atmosphere-ocean general circulation model (AOGCM) ECHAM5/MPI-OM [Roeckner et al., 2003; Marsland et al., 2003] and the regional atmospheric model REMO [Jacob, 2001; Jacob et al., 2001], all developed at Max Planck Institute for Meteorology. The GCM model is in this application a spectral model with an equivalent horizontal resolution of $3.75^{\circ}$ and 20 unequally spaced levels. The ocean component is a grid point model of $3^{\circ}$ and 40 unequally spaced levels. The regional climate model is in this application a grid point model with an equivalent horizontal resolution of $0.5^{\circ}$ and 20 terrain-following vertical levels based on primitive equations.

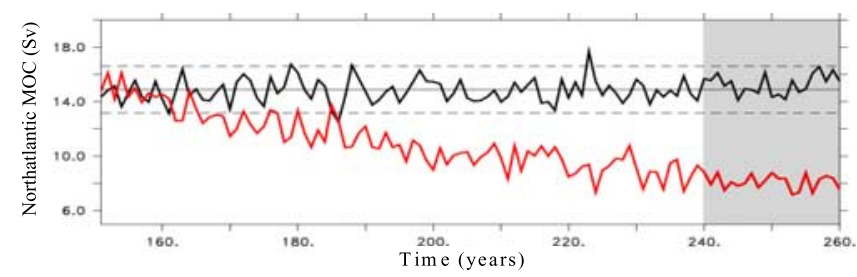

Figure 1. Time evolution of $\mathrm{THC}$ strength at $30^{\circ} \mathrm{N}$ : control experiment (CTRL) in black and run with additional freshwater flux (FW) in red. The shading in the last 20 years marks the period of nesting for the CRTL and FW experiments. 


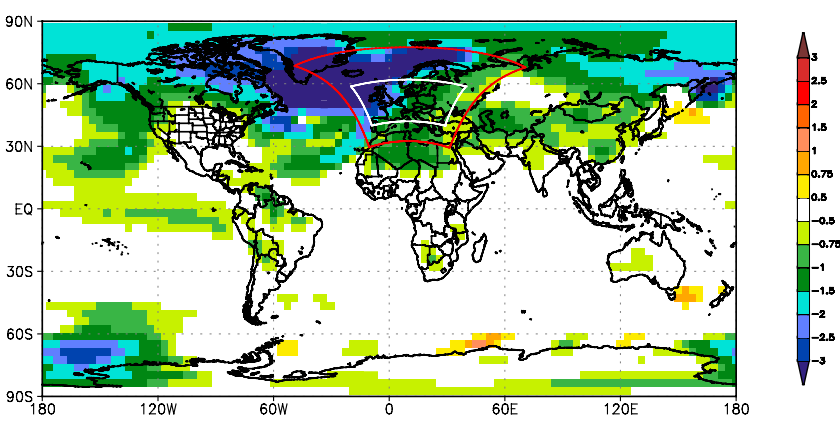

Figure 2. Annual-mean near-surface air temperature difference, FW minus CTRL, averaged over 20 years, for global model (red box - domain for regional run; white box - analysis area).

[4] The coupled control simulation (CTRL) under preindustrial greenhouse gas conditions is run for 260 simulated years and maintains a stable climate without flux adjustments; in particular the THC strength is statistically steady with a mean of $15 \mathrm{~Sv}$ (Figure 1), slightly lower than observed [Ganachaud and Wunsch, 2000]. Maximum global and Atlantic meridional oceanic heat transports in the Northern Hemisphere are at realistic 2 PW (1 PW $\equiv$ $10^{15} \mathrm{~W}$ ) and $0.9 \mathrm{PW}$, respectively. In the perturbation run (FW), a freshwater flux of $0.1 \mathrm{~Sv}$ is spread over the surface North Atlantic between $50^{\circ} \mathrm{N}$ and $70^{\circ} \mathrm{N}$ at year 150 of the control run; during the following 110 years, the THC strength is reduced to $8 \mathrm{~Sv}$ (Figure 1). Data from the last 20 years of both global runs are used as boundary forcing for the regional model.

[5] The THC decrease in the perturbation run causes a reduction of the maximum meridional heat transport from 0.9 to $0.6 \mathrm{PW}$ (not shown), resulting in surface cooling in the North Atlantic sector of more than $3^{\circ} \mathrm{C}$ (Figure 2 displays near-surface air temperature, which is very close to the SST). Similar cooling also occurs in the North and South Pacific, though in much more restricted areas.

[6] The dynamical downscaling permits the analysis of temperature change with considerably higher spatial detail; in addition, some shifts occur in the cooling pattern (Figure 3). Statistically significant cooling results from the halving of THC strength in FW for all of western and northern Europe, whereas the cooling in southern and eastern Europe is not significant. Over a large area, mean winter temperatures (December, January, February) fall below the control run means by 1.5 degrees and more. Temperature of an average winter in London, for example, drops by about $2.4^{\circ} \mathrm{C}$, a change comparable to the coldest winter on record in central England, which was $2.7^{\circ} \mathrm{C}$ colder than average [Parker et al., 1992].

[7] Concomitant with the temperature decrease for Europe of about $1.7 \mathrm{~K}$ in winter and $1 \mathrm{~K}$ in summer, precipitation also decreases, particularly in summer (Table 1). The general decrease is consistent across both models, but there is no clear tendency in the difference between the models. The temperature decrease in winter is stronger than in summer, which is caused by cold maritime air masses travelling further inland in winter than in summer (or stronger maritime influence in winter than in summer). The decrease in temperature is associated with a decrease in precipitation, in summer stronger than in winter. This is consistent with the Clausius-Clapeyron relation, according to which a decrease in temperature by the same amount is accompanied by a considerably stronger decrease in humidity in summer than in winter. The most dramatic change, however, occurs not in the total amount of precipitation but in the snow portion of it (Table 1), as well as in snow cover (Figure 4). Also, we see here the clearest difference between the models, with the regional model predicting a much larger fraction of snow in precipitation than the global model; owing to the higher resolution and better ability to simulate regional orographic features, we ascribe greater realism to the regional model. Throughout Europe, with the exception of the westernmost parts, we thus find that snow constitutes the majority of winter precipitation (Table 1); snow fraction increases by generally 50 to $100 \%$. This leads to considerably enhanced snow cover over Europe - almost all of Britain would, in this sensitivity experiment, experience more than 10 "snow days" a year, defined here as a day with more than $3 \mathrm{~cm}$ water equivalent of snow cover. In contrast, CTRL shows more than 10 snow days in Britain only at higher altitudes toward the north. In continental Europe, the 10-snow day line moves from its current position through the middle of Germany, by 300 to $500 \mathrm{~km}$ to the west. The change in snow cover leads to an increase in albedo, especially over Scandinavia, northern Germany and Britain, and all mountainous areas in southern central Europe (Figure 4).

[8] The influence of climate change on societies is expected to manifest itself through a change in extremes. In experiment FW, the number of summer and hot days drops, particularly in southern Britain, whereas the number of frost and ice days increases significantly throughout Europe (Table 2). As a consequence, the annual energy consumption would be expected to change as well. A convenient measure of energy consumption for heating purposes is the number of degree days following EUROSTAT [Diekmann and Ziesing, 1998]. Table 2 shows that in experiment FW, heating energy consumption would rise by about $20 \%$ in London and by about $10 \%$ in Europe. Both increases are significant at the $95 \%$ level. Notice that average Europe summer cooling degree days drop in FW, from 327 to 313 , but this drop is not statistically significant.

[9] The number of zonal cyclone tracks increases in experiment FW, compared to CTRL. This is very clear over Britain, where the low-pressure systems are advecting colder and drier air masses, delivering more snow than rain in winter. However, the total amount of precipitation (solid and liquid) is less than in CTRL. In Central Europe the low-pressure systems on zonal tracks move further inland before turning northeastward or northward. Finally the air masses join the cold air over North-East Europe, and almost no change in snow cover can be detected.

[10] The change in storm track statistics [Muskulus and $J a c o b, 2005]$ can partly be explained by a change in the atmospheric circulation pattern over the Atlantic (Figure 5). In experiment $\mathrm{FW}$, the Icelandic Low deepens and the Azores High strengthens, meaning that the North Atlantic 

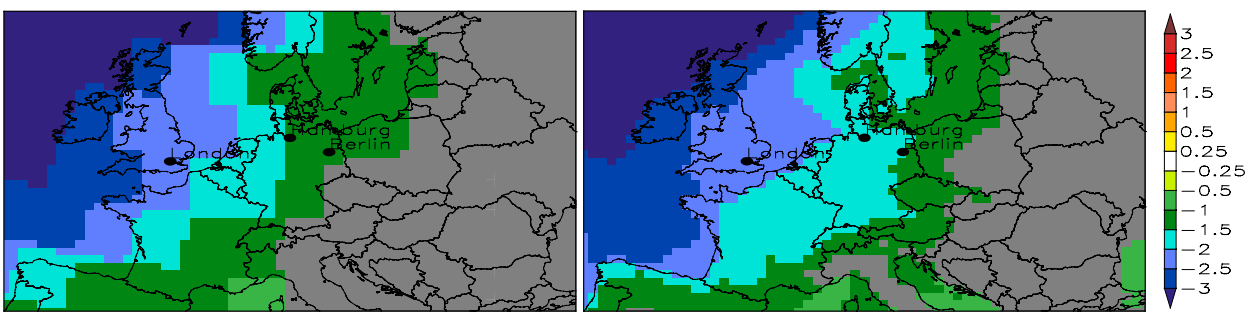

Figure 3. Annual-mean near-surface air temperature difference, FW minus CTRL, averaged over 20 years, for (left) global model and (right) regional model. Shown in colour are only values with greater than $95 \%$ confidence.

Table 1. Differences, FW Minus CTRL, in Relative Percentage Change in Precipitation and in the Snow Part of Precipitation for Seasonal Means Over 20 years, for Some Countries and Cities (Value of Nearest Neighbour), for the Global (First Entries) and Regional (Second Entries) Models

\begin{tabular}{|c|c|c|c|c|c|}
\hline & London & Karlsruhe & Europe & UK & Germany \\
\hline \multicolumn{6}{|c|}{ Rain } \\
\hline Winter & $-4.3 /-9 \%$ & $-15 /-9 \%$ & $-13 /-9 \%$ & $-3 /-9 \%$ & $-15 /-10 \%$ \\
\hline Spring & $-0.4 /-13 \%$ & $-11 /-2 \%$ & $-10 /-10 \%$ & $-0.1 /-12 \%$ & $-8 /-4 \%$ \\
\hline Summer & $-18 /-21 \%$ & $-24 /-16 \%$ & $-21 /-14 \%$ & $-11 /-18 \%$ & $-21 /-15 \%$ \\
\hline Autumn & $-6 /-7 \%$ & $-17 /-3 \%$ & $-10 /-9 \%$ & $-2 /-7 \%$ & $-14 /-8 \%$ \\
\hline \multicolumn{6}{|c|}{ Snow Part of Rain } \\
\hline \multirow[t]{2}{*}{ Winter } & $6 \% \rightarrow 16 \%$ & $29 \% \rightarrow 50 \%$ & $41 \% \rightarrow 54 \%$ & $6 \% \rightarrow 18 \%$ & $38 \% \rightarrow 57 \%$ \\
\hline & $19 \% \rightarrow 41 \%$ & $41 \% \rightarrow 69 \%$ & $58 \% \rightarrow 72 \%$ & $29 \% \rightarrow 60 \%$ & $59 \% \rightarrow 81 \%$ \\
\hline \multirow[t]{2}{*}{ Spring } & $2 \% \rightarrow 5 \%$ & $8 \% \rightarrow 12 \%$ & $13 \% \rightarrow 17 \%$ & $2 \% \rightarrow 7 \%$ & $11 \% \rightarrow 16 \%$ \\
\hline & $8 \% \rightarrow 16 \%$ & $14 \% \rightarrow 29 \%$ & $28 \% \rightarrow 39 \%$ & $13 \% \rightarrow 37 \%$ & $23 \% \rightarrow 39 \%$ \\
\hline \multirow[t]{2}{*}{ Summer } & & & $0 \% \rightarrow 0 \%$ & & \\
\hline & & & $0 \% \rightarrow 1 \%$ & & \\
\hline \multirow[t]{2}{*}{ Autumn } & $0.2 \% \rightarrow 11 \%$ & $4 \% \rightarrow 11 \%$ & $10 \% \rightarrow 15 \%$ & $0.2 \% \rightarrow 2 \%$ & $6 \% \rightarrow 12 \%$ \\
\hline & $2 \% \rightarrow 5 \%$ & $4 \% \rightarrow 13 \%$ & $15 \% \rightarrow 23 \%$ & $3 \% \rightarrow 12 \%$ & $8 \% \rightarrow 18 \%$ \\
\hline
\end{tabular}

Table 2. Extreme Days for CTRL and FW for Yearly Sum Over 20 Years $^{\mathrm{a}}$

\begin{tabular}{|c|c|c|c|c|c|c|}
\hline & \multicolumn{2}{|c|}{ London } & \multicolumn{2}{|c|}{ Karlsruhe } & \multicolumn{2}{|c|}{ Europe } \\
\hline & CTRL & FW & CTRL & FW & CTRL & FW \\
\hline $\begin{array}{l}\text { Warm days } \mathrm{T}_{ø}>20^{\circ} \mathrm{C} \\
\text { Degree days } \sum 20^{\circ} \mathrm{C}-\bar{T}\left(<15^{\circ} \mathrm{C}\right)\end{array}$ & $\begin{array}{c}6.4^{5.5} \\
3687^{231}\end{array}$ & $\begin{array}{l}1.1^{1.7} \\
4525^{343}\end{array}$ & $\begin{array}{l}20.3^{7.7} \\
4007^{302}\end{array}$ & $\begin{array}{c}15^{11.4} \\
4661^{390}\end{array}$ & $\begin{array}{l}26.3^{4.0} \\
4756^{286}\end{array}$ & $\begin{aligned} 23.3^{3.6} \\
5282^{222}\end{aligned}$ \\
\hline Snowdays & 3 & 27 & 24 & 120 & 69 & 179 \\
\hline
\end{tabular}

${ }^{\text {a }}$ The standard deviations of the yearly distribution are shown in superscripts. 


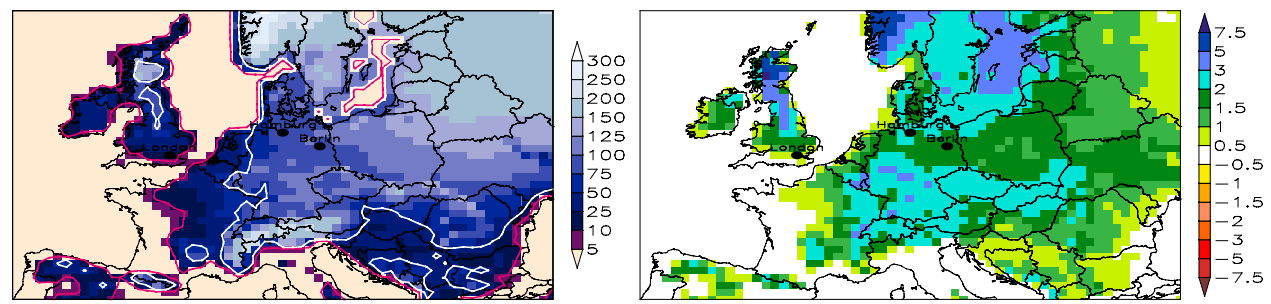

Figure 4. (left) Number of "snow days" over fraction of land, with a snow cover of more than $3 \mathrm{~cm}$ water equivalent, for annual mean over 20 years. The area with more than 10 snow days per year is marked by the white (CTRL) and purple (FW) lines. (right) Albedo difference, in percentage points, FW minus CTRL.

Oscillation (NAO) index increases. The increased pressure difference results in more and stronger winter storms crossing the Atlantic Ocean on a more northerly track, leading to more strongly maritime dominated winters in Europe. Under today's THC conditions (CTRL), the maritime influence leads to warm and wet winters in Europe. However, with the weaker THC of FW, stronger maritime influence means stronger effect of the lower sea surface temperatures (SST) - compared to CTRL, colder and drier air masses are advected into Central Europe. This influence is weaker for Norway, which is partly influenced by cold and dry sub-arctic air masses under low NAO index.

\section{Conclusions}

[11] Our results are not directly applicable to the consequences of THC changes under enhanced greenhouse gas concentrations [Cubasch et al., 2001]. Instead, they address the consequences of THC change in a "current climate" setting, or those following a moderate meltwater discharge. However, through the nesting of a regional climate model into a global THC slowdown sensitivity experiment, we have shown that a considerable weakening of the Atlantic THC would be expected to have significant influence on continental as well as coastal Europe. In particular, the changes in atmospheric circulation lead to enhanced mari-

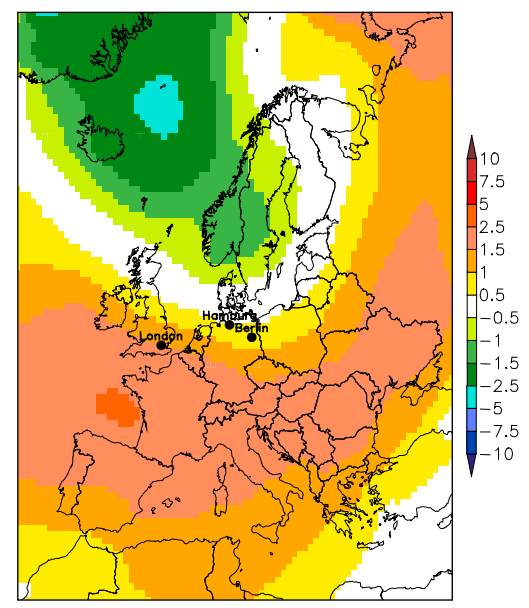

Figure 5. Winter sea level pressure difference, FW minus CTRL, averaged over 20 years. time climate influence over Europe which, surprisingly cools rather than warms. A weakening of the THC triggers a positive feedback loop, involving more snow days, an increase in albedo, and higher reflection of sunlight leading to further cooling. This could be considered a regional version of the global feedback proposed for the inception of the last glaciation [Khodri et al., 2001]. The quantitative role of his feedback has to be evaluated over longer timescales, but must also be compared to the tundra-taiga feedback [McFadden and Ragotzkie, 1967; Betts and Ball, 1997] for efficiency and response time.

\section{References}

Aagard, K., and C. E. Carmack (1989), The role of sea ice and other fresh water in the Arctic circulation, J. Geophys. Res., 94, 14,485-14,498.

Betts, A. K., and J. H. Ball (1997), Albedo over the boreal forest, J. Geophys. Res., 102, 28,901-28,909.

Clarke, G. K. C., D. W. Leverington, J. T. Teller, and A. S. Dyke (2004), Paleohydraulics of the last outburst flood from glacial Lake Agassiz and the 8200 BP cold event, Quat. Sci. Rev., 23, 389-407.

Cubasch, U., et al. (2001), Projections of future climate change, in Climate Change 2001: The Scientific Basis. Contribution of Working Group I to the Third Assessment Report of the Intergovernmental Panel on Climate Change, edited by J. T. Houghton et al., pp. 525-582, Cambridge Univ. Press, New York.

Diekmann, J., and H. J. Ziesing (1998), The Determination of a Common Method for the Climatic Correction of Energy Consumption Data in the $E U$, Eur. Comm., Brussels.

Fairbanks, R. G. (1989), A 17,000-year glacio-eustatic sea-level recordInfluence of glacial melting rates on the Younger Dryas event and deepocean circulation, Nature, 342, 637-642.

Ganachaud, A., and C. Wunsch (2000), Improved estimates of global ocean circulation, heat transport and mixing from hydrographic data, Nature, $408,453-457$.

Greve, R. (2000), On the response of the Greenland ice sheet to greenhouse climate change, Clim. Change, 46, 289-303.

Huybrechts, P., and J. de Wolde (1999), The dynamic response of the Greenland and Antarctic ice sheets to multiple-century climatic warming, J. Clim., 12, 2169-2188.

Jacob, D. (2001), A note to the simulation of the annual and inter-annual variability of the water budget over the Baltic Sea drainage basin, Meteorol. Atmos. Phys., 77, 61-73.

Jacob, D., et al. (2001), A comprehensive model inter-comparison study investigating the water budget during the BALTEX-PIDCAP period, Meteorol. Atmos. Phys., 77, 19-43.

Khodri, M., et al. (2001), Simulating the amplification of orbital forcing by ocean feedbacks in the last glaciation, Nature, 410, 570-574.

Manabe, S., and R. J. Stouffer (1995), Simulation of abrupt climate change induced by freshwater input to the North Atlantic Ocean, Nature, 378, $165-167$.

Marsland, S. J., H. Haak, J. H. Jungclaus, M. Latif, and F. Röske (2003), The Max-Planck-Institute global ocean/sea ice model with orthogonal curvilinear coordinates, Ocean Modell., 5, 91-127.

McFadden, J. D., and R. A. Ragotzkie (1967), Climatological significance of albedo in central Canada, J. Geophys. Res., 72, 1135-1143.

McManus, J. F., R. Francois, J. M. Gherardi, L. D. Keigwin, and S. BrownLeger (2004), Collapse and rapid resumption of Atlantic meridional circulation linked to deglacial climate changes, Nature, 428, 834-837. 
Mikolajewicz, U., T. J. Crowley, A. Schiller, and R. Voss (1997), Modelling teleconnections between the North Atlantic and North Pacific during the Younger Dryas, Nature, 387, 384-387.

Muskulus, M., and D. Jacob (2005), Tracking cyclones in regional model data: The future of Mediterranean storms, Adv. Geosci., 2, 13-19.

Parker, D. E., T. P. Legg, and C. K. Folland (1992), A new daily central England temperature series, 1772-1991, Int. J. Climatol., 12, $317-$ 342.

Roeckner, E., et al. (2003), The atmospheric general circulation model ECHAM5. Part I: Model description, MPI Rep. 349, 127 pp., Max Planck Inst. for Meteorol., Hamburg, Germany.
Teller, J. T., and D. W. Leverington (2004), Glacial Lake Agassiz: A $5000 \mathrm{yr}$ history of change and its relationship to the delta O-18 record of Greenland, Geol. Soc. Am. Bull., 116, 729-742.

Vellinga, M., and R. A. Wood (2002), Global climate impacts of a collapse of the Atlantic thermohaline circulation, Clim. Change, 54, 251-267.

H. Goettel, D. Jacob, J. Jungclaus, J. Marotzke, M. Muskulus, and R. Podzun, Max Planck Institute for Meteorology, Bundesstrasse 53, D-20146 Hamburg, Germany. (jacob@dkrz.de) 